\title{
Modification of Gentle Human Touch (GHT) With Left Lateral Position to Change the Frequency of Breath Among Low Birth Weight (LBW) Infants
}

\author{
$1^{\text {st }}$ Agi Yulia Riadini \\ Midwifery Department \\ Sekolah Tinggi Ilmu Kesehatan Cirebon \\ Cirebon, Indonesia \\ agiyulia.strkeb@gmail.com \\ $4^{\text {th }}$ Ika Choirin Nisa \\ Midwifery Department \\ Sekolah Tinggi Ilmu Kesehatan Cirebon \\ Cirebon, Indonesia
}

\author{
$2^{\text {nd }}$ Agus Suwandono \\ Postgraduate Public health program \\ Universitas Diponegoro \\ Semarang, Indonesia \\ $5^{\text {th }}$ Heny Puspasari \\ Midwifery Department \\ Sekolah Tinggi Ilmu Kesehatan Cirebon \\ Cirebon, Indonesia
}

\author{
$3^{\text {rd }}$ Runjati \\ Postgraduate Midwifery Program \\ Poltekkes Kemenkes Semarang \\ Semarang, Indonesia
}

\begin{abstract}
Long period LBW treatment in a hospital often causes stress which results in changes in physiological function. Modification of gentle human touch with left lateral position is a treatment that supports in providing comfort and good position for the lungs that affect thoracoabdominal synchronization and respiratory ventilation which are expected to promote a positive effect on respiration rate among infants. This study aims to prove the difference in the effect of modification of GHT with left lateral position and gentle human touch with supine position on respiration rate among LBW infants. This study used a Quasy Experimental Design. The populations in this study were all LBW infants in Brebes District General Hospital and Bhakti Asih Hospital as many as 36 infants who were collected using purposive sampling technique. The statistical test used was general linear model. The GHT with supine position was more influential in stabilizing the respiration rate among $\mathrm{LBW}$ infants compared to the modification of GHT with left lateral position. Conclusion: GHT with supine position is more influential on the frequency of LBW infants so that it can be used as LBW treatment in hospitals and at home to meet the needs of touch among infants.
\end{abstract}

Keywords-Gentle Human Touch (GHT), Lateral Position, Low Birth Weight (LBW)

\section{INTRODUCTION}

Low Birth Weight Infants is one of the complications among infants as a contributor to infant mortality. Low birth weight (LBW) infants are infants born with less than 2500 grams of weight regardless of gestational age. ${ }^{[1]}$ Low birth weight (LBW) infants have many risks of experiencing problems in the body system, due to unstable body conditions. Perinatal mortality in LBW infants is 8 times greater than in normal infants. ${ }^{[2]}$

Deaths that occur among low birth weight infants (LBW) are caused by problems including due to central respiratory regulation and imperfect digestive devices, low metabolic ability so that it can cause asphyxia, acidosis and infection easily, especially the risk of morbidity and mortality due to lower respiratory tract infections. ${ }^{[3]}$ In addition to the risk of death, LBW infants also have a risk of health problems mainly due to organ maturation in LBW infants with prematurity. Problems or health problems that occur in LBW infants early in life include hyaline membrane disease, asphyxia, intracranial hemorrhage, neurological disorders, hypothermia, metabolic disorders and a tendency for neonatal infections. ${ }^{[4]}$

Medical and technological developments as the efforts to improve survival in premature and LBW infants are continued to develop, however, many of the procedures that are part of the hospital care often cause discomfort among infants during the period of treatment and cause changes in the physiological functions of infants such as hypothermia, increased and heart rate, recurrent apneic events and the decrease in the percentage of oxygen-bound hemoglobin (SpO2) and cause increase in oxygen supplementation needs. ${ }^{[1]}$ A study conducted in Africa showed that LBW with prolonged use of oxygen had a risk factor for retinopathy of prematurity (ROP). ${ }^{[2]}$

LBW infants treatment in perinatology ward has focused more on thermoregulation settings where infants are placed in incubators or transwarmer mattress. ${ }^{[3]}$ Treatment in incubators is quite effective in preventing hypothermia, but treatment in incubators with supine position and minimal positive touch is not influential in managing baby's stress and improving lung function and baby's breathing patterns. Therefore we need an environmental management strategy that can also be done to reduce stress as a result of this excessive nursing environment stimulus namely by developmental care. Developmental care can be used to minimize the negative effects of care on infants at hospital, one example is by positioning. ${ }^{[4]}$

Supine position is the position most often applied to infants during the care period, but this position is less favorable for premature LBW infants, this is because the supine position does not support the flexion position and can increase stress in the baby, while there is a risk of SIDS in prone position among newborns. ${ }^{[5]}$ The position which is able to facilitate the baby to be in a position of flexion and to benefit the baby's lungs is left lateral position. Lateral 
position is a position similar to the position of the baby in the uterus.[4] A study conducted among 19 infants found that oxygen saturation in infants who were given a lateral left position was higher when compared to the supination position. Routine care and excessive handling of infants were associated with increased incidence of hypoxia, increased intracranial pressure, apne/bradycardia, agitation, increased or decreased heart frequency or blood pressure among infants. Therefore we need touch therapy in the form of gentle human touch that can be done during the treatment period to facilitate changes in position (positioning) so that the baby can adapt outside the uterus. ${ }^{[4]}$

Gentle human touch (GHT) is a complementary therapy in the form of non-invasive touch without stroking or massaging that is easily combined with other therapies.[6] Touch is the first sense that develops at 7 weeks of gestation and is the foundation for the development of verbal communication, learning, regulation and social interaction ${ }^{[7 .}$ In the application of GHT, one hand is placed on the baby's head and the other hand is placed on the baby's stomach to provide a relaxing effect on the baby. The use of GHT has been reported to reduce energy expenditure in infants as evidenced by decreased levels of motor activity or improved sleep quality after being given care in the form of gentle human touch. ${ }^{[6]}$

An experimental study conducted on 90 infants at Asfali Pour Hospital aimed at comparing yaxon and GHT therapy showed that there were significant changes in the sleep status of preterm infants after being given GHT in the intervention group and there were no significant differences in the sleep status of the GHT between the intervention group and the Yakson intervention group. ${ }^{[8]}$ Other study on the benefits of touch therapy also found that the use of a combination of music and touch therapy could increase serum $\beta$ endhorphin levels which caused a reduced response to pain, but cortisol levels in the blood did not differ significantly after being treated with touch therapy. ${ }^{[9]}$ A study conducted on 13 premature infants carried out for 12 minutes 4 times a day showed an increase in hematocrit levels and infants who were given GHT needed less oxygen than the infants who were not given GHT. ${ }^{[10]}$
Efforts to care for low birthweight and preterm infants in both the NICU ward and the nursing room often stress the baby due to noisy treatment environments and painful actions. ${ }^{[11]}$ Modification of gentle human touch with the left lateral position is a complementary modality based on science that is used to support the comfort that is expected to have a positive effect on oxygen saturation and the baby's respiratory rate. By looking at the background description above, a study is needed to determine the effect of modification of GHT therapy with lateral position on the respiration rate among $\mathrm{LBW}$ infants.

\section{METHODS}

This study used Quasy Experimental Design. The number of samples of this study was $36 \mathrm{LBW}$ collected with purposive sampling technique. The samples were assigned two groups namely the treatment group that was given modification of gentle human touch with left lateral position and the control group that was given gentle human touch with supine position.

\section{RESULTS}

\section{A. Prerequisite Analysis}

Normality test was carried out on pretest and posttest data based on days so that there were 5 pretest data and 5 posttest data to be processed with normality test using Shapiro Wilk. Data normality on the mean respiration rate showed that $\mathrm{p}>$ 0.05 which meant that the data were normally distributed.

Homogeneity test was performed on the respiration rate data on the first day before the infants received intervention in each group. Initial data on the respiration rate both in the intervention and control groups had equal or homogeneous distribution.

\section{B. Univariate Analysis}

Characteristics of Respondents Research data were collected from the intervention group and the control group. Data on the characteristics of LBW infants are presented in the table below:

TABLE 1. CHARACTERISTICS OF LBW INFANTS

\begin{tabular}{|c|c|c|c|c|c|}
\hline \multirow[b]{2}{*}{ Variable } & \multicolumn{2}{|c|}{ Intervention } & \multicolumn{2}{|c|}{ Control } & \multirow[t]{2}{*}{$\mathrm{P}^{*}$} \\
\hline & $\mathrm{n}(\%)$ & Mean \pm SD & $\mathrm{n}(\%)$ & Mean \pm SD & \\
\hline Birth Status & & & & & 0.025 \\
\hline Premature & $15(83.3 \%)$ & & $12(66.72 \%)$ & & \\
\hline Mature & $3(16.7 \%)$ & & $6(33.3 \%)$ & & \\
\hline Sex & & & & & 0.073 \\
\hline Female & $8(44.4 \%)$ & & $13(72.2 \%)$ & & \\
\hline Male & $10(55.6 \%)$ & & $5(27,8 \%)$ & & \\
\hline Body Weight (gr) & & $1894 \pm 268.59$ & & $2030 \pm 339.012$ & 0.163 \\
\hline
\end{tabular}

Table 1 shows the characteristics of LBW in the two groups. The results showed that the status of birth was at most premature (27 infants) and female (21 infants) was more than male. Baby weight data showed that the mean weight in the 
intervention group was 1894 grams while the control group was 2030 grams. For homogeneity test, the significance value of birth status variable was $<0.05$. This showed that the birth status variable in the two groups was not homogeneous, while the other variables namely sex and body weight in both groups showed $\mathrm{p}$ values of $>0.05$. This showed that the variable had a homogeneous data distribution.

\section{Bivariate Analysis}

Details of the results of data analysis that support the second hypothesis can be seen from the table of changes in respiration rate for 5 days in the intervention and control groups below:

TABLE 2. DIFFERENCE IN RESPIRATION RATE BEFORE AND AFTER INTERVENTION BY GROUP

\begin{tabular}{|c|c|c|c|c|}
\hline \multirow{3}{*}{ Day } & \multirow{3}{*}{ Respiration Rate } & \multicolumn{2}{|c|}{ Group } & \multirow[t]{3}{*}{$\mathrm{P}$ value $^{\mathrm{a}}$} \\
\hline & & Intervention & Control & \\
\hline & & Mean \pm SD & Mean \pm SD & \\
\hline \multirow[t]{3}{*}{ Day 1} & Pretest 1 & $49 \pm 3.243$ & $48 \pm 3.599$ & \multirow[t]{2}{*}{0.002} \\
\hline & Posttest 1 & $50 \pm 3.215$ & $48 \pm 3.236$ & \\
\hline & $\Delta$ & $1,50 \pm 1,600$ & $-0,19 \pm 1,352$ & \\
\hline \multirow[t]{3}{*}{ Day 2} & Pretest 2 & $48 \pm 2.904$ & $49 \pm 3.379$ & \multirow[t]{2}{*}{0.002} \\
\hline & Posttest 2 & $50 \pm 2.311$ & $49 \pm 3.422$ & \\
\hline & $\Delta$ & $1.47 \pm 1.334$ & $0.08 \pm 1.179$ & \\
\hline \multirow[t]{3}{*}{ Day 3} & Pretest 3 & $50 \pm 2.541$ & $49 \pm 4.018$ & \multirow[t]{2}{*}{0.150} \\
\hline & Posttest 3 & $51 \pm 2.504$ & $49 \pm 3.623$ & \\
\hline & $\Delta$ & $0.83 \pm 1.732$ & $-0,08 \pm 1.994$ & \\
\hline \multirow[t]{3}{*}{ Day 4} & Pretest 4 & $49 \pm 3.151$ & $49 \pm 3.384$ & \multirow[t]{2}{*}{0.012} \\
\hline & Posttest 4 & $51 \pm 2.876$ & $49 \pm 3.452$ & \\
\hline & $\Delta$ & $1,44 \pm 1,434$ & $-0,03 \pm 1,882$ & \\
\hline \multirow[t]{3}{*}{ Day 5} & Pretest 5 & $51 \pm 2.551$ & $49 \pm 3.503$ & \multirow[t]{2}{*}{0.031} \\
\hline & Posttest 5 & $52 \pm 2,184$ & $49 \pm 3,466$ & \\
\hline & $\Delta$ & $0.94 \pm 1.338$ & $-0.17 \pm 1.618$ & \\
\hline
\end{tabular}

Different test result in the unpaired group in the oxygen saturation variable. Statistical test result using general linear model showed that the measurement of respiration rate on the first day to the fifth day obtained $p$ value of $<0.05$ so that it can be concluded that there was a difference in respiration rate between the group of modification of gentle human touch with left lateral position and the group of gentle human touch with supine position. Respiration rate values for 5 days in each group were in the normal range of $50 \mathrm{x} / \mathrm{min}$. LBW without complication has normal respiration rate of $30 \mathrm{x} / \mathrm{min}$ to $60 \mathrm{x} / \mathrm{min}$.

\section{DISCUSSION}

Based on statistical test to distinguish the effect between the two groups, the results obtained p value $<0.05$, this meant that there was a difference in the effect on the respiration rate among LBW infants between the intervention group and the control group. When it is deeper observed, the clinical changes that occurred in the intervention group and the control group showed a difference between the two. On the average, the infants who received gentle human touch modification with left lateral position showed an increase in the respiration rate value, however the increase or decrease in respiration rate in the group of gentle human touch modification with left lateral position was still within the normal threshold of infant respiration rate $(30 \mathrm{x} / \mathrm{min}$ up to $60 \mathrm{x} / \mathrm{min})$. In contrast, On the average, the infants in the control group who received gentle human touch with supine position showed no change in the respiration rate and it tended to be stable at $49 \mathrm{x} / \mathrm{min}$.

Respiratory stabilization and optimization of oxygenation after birth are essential for long-term survival and health of infants.[5] Premature LBW infants have problems due to immature organ function, making them at risk of ventilation, collapsed alveolar collapse and decreased residual volume. lung. Many studies that have focused on the care of premature infants have tried to examine positionrelated effects on vital signs such as activity on cardiorespiration, oxygenation, lung function and respiratory rate and have shown positive results for position-related effectes on infant breathing.

Position plays an important role in lung function, digestion and autonomic function of premature infants. The baby position with his arms and legs flexed in line with the midline of the body is the recommended position for the infant. Regarding the mechanism of left lateral position, several studies among adult patients and premature infants suggested that the prone position could increase lung volume through lung expansion in the back region caused by decreased abdominal weight transmission to the dorsal region and decreased pulmonary compression by the heart. In a study which compared the positions of prone, lateral left and supination among premature infants, it was found that left lateral position had the same effect as the prone position 
to improve the lung function of the newborn through thoracoabdominal synchronization. Better thoracoabdominal synchronization in left lateral position compared to supine position was indicated from the low value of $\theta$ (the angular phase between abdominal and thoracic movements) in supination compared to left lateral position, whereas the RC\% value (rib contribution to Tidal volume) in supine position was also lower than left lateral position. From the two values it could be concluded that thoracoabdominal synchronization was better than supine position.[10] In left lateral position, the expansion of the right lung is expected to be the same as the prone position which provides optimization of the function of LBW baby's lungs.

LBW treatment in hospitals often causes discomfort as a cause of stress which results in changes in physiological function. Giving gentle human touch which is one type of tactile stimulation that has a relaxing effect on the baby. Gentle Human Touch (GHT) is a method of gentle contact with the skin without stroking or massaging. It has been reported from several studies that GHT can improve sleep quality during and after interventions. Increasing the quality of sleep and comfort will help the baby overcome his physical weakness by accelerating recovery. ${ }^{[11]}$ The comfort that comes from giving gentle human touch will optimize thoracoabdominal synchronization and make the respiration rate stable.

Studies related to midwifery measures to stabilize the respiration rate included the study on the kangaroo and nesting methods. A study on LBW infants who were given KMC (kangaroo Mother Care) with a combination of music therapy for respiration rate showed that KMC could maintain a stable respiration rate.

The combination of KMC with music therapy was able to provide respiration rate stability at $43 \mathrm{x} / \mathrm{min}$ with an effect size value of 0.02 , which meanst that the combination of KMC with music therapy had a small effect on stabilizing the respiration rate among LBW infants ${ }^{[7]}$ Furthermore, a study on the semi prone position among preterm infants for respiratory stabilization showed that the semi prone position was able to provide respiration rate stability at $44 \mathrm{x} / \mathrm{min}$ with an effect size value of 0.1 which meant that the semi prone position had a small effect on stabilizing the infant's respiration rate. ${ }^{[9]}$

\section{CONCLUSION}

Gentle human touch with supine position was more influential in stabilizing respiration rate compared to modification of gentle human touch with left lateral position.

Gentle human touch with supine position can be used as a developmental care for LBW infants with the criteria that the baby is in a stable condition such as no longer using breathing aids and oxygen, the operator should be nurses or midwives who have been trained and accustomed to infants management in the NICU or perinatology ward.

Further studies need to control the external factors that affect changes in oxygen saturation and respiration rate such as hemoglobin values, hematocrit and bilirubin levels of the infants during treatment.

\section{REFERENCES}

[1] J. Vinall and R. E. Grunau, "Impact of repeated procedural painrelated stress in infants born very preterm," Pediatr. Res., vol. 75, no. 5, pp. 584-587, 2014.

[2] A. Hakeem, G. Mohamed, and M. Othman, "Retinopathy of prematurity: A study of prevalence and risk factors," Middle East Afr. J. Ophthalmol., vol. 19, no. 3, pp. 289-294, 2012.

[3] A. Nosherwan, P. Y. Cheung, and G. M. Schmölzer, "Management of Extremely Low Birth Weight Infants in Delivery Room," Clin. Perinatol., vol. 44, no. 2, pp. 361-375, 2017.

[4] P. P. Trihono et al., Pelayanan Kesehatan Anak Terpadu. 2013.

[5] R. Bayuningsih, "Efektivitas penggunaan nesting dan prone terhadap saturasi oksigen dan frekuensi nadi pada bayi prematur di RSUD Kota Bekasi," Univ. Indones., 2017.

[6] H. Im, E. Kim, and K. C. Cain, "Acute effects of Yakson and Gentle Human Touch on the behavioral state of preterm infants," J. Child Heal. Care, vol. 13, no. 3, pp. 212-226, 2009.

[7] J. R. Smith, "Comforting touch in the very preterm hospitalized infant: An integrative review," Adv. Neonatal Care, vol. 12, no. 6, pp. 349-365, 2012.

[8] B. Bahman Bijari, S. Iranmanesh, F. Eshghi, and M. R. Baneshi, "Gentle Human Touch and Yakson: The Effect on Preterm's Behavioral Reactions," ISRN Nurs., vol. 2012, pp. 1-6, 2012.

[9] R. Qiu, J., Jiang, Y.-f., Li, F., Tong, Q.-h., Rong, H., and Cheng, "Effect of combined music and touch intervention on pain response and $\beta$-endorphin and cortisol concentrations in late preterm infants," BMC Pediatr., 2017.

[10] L. L. Harrison, "The use of comforting touch and massage to reduce stress for preterm infants in the neonatal intensive care unit," Newborn Infant Nurs. Rev., vol. 1, no. 4, pp. 235-241, 2001.

[11] L. Provenzi et al., "Pain-related stress during the neonatal intensive care unit stay and SLC6A4 methylation in very preterm infants," Front. Behav. Neurosci., vol. 9, no. APR, pp. 1-9, 2015. 